\title{
AGE AND GENDER DIFFERENCES IN HEALTH RISK PERCEPTION
}

\author{
YoungHo Kim, InKyoung Park, SooJin Kang \\ Department of Sport Science, Seoul National University of Science and Technology, Seoul, Korea
}

\begin{abstract}
SUMMARY
Objective: The current study investigated how adolescents perceive their own health risks and compare their own likelihood of health risks with that of others of the same age. Moreover, the study identified the differences in health risk perceptions between males and females.

Methods: A total of 625 adolescents (314 males and 311 females) from the Nowon district, geographically located in northern Seoul, voluntarily participated. In order to measure health risk perceptions a Korean version of self-other risk judgments profile was used.

Results: The findings indicated that study participants, regardless of gender and age, tend to underestimate their vulnerability to majority of health risk events. Furthermore, there were significant gender and age differences in health risk perception and perception bias in all health risk domains.

Conclusion: The present study suggests that further research is needed to identify realistic and unrealistic perception mechanism for a large number of people from different demographic and socioeconomic backgrounds.
\end{abstract}

Key words: adolescents, risk perception, perception bias, health risks, gender, age

Address for correspondence: SooJin Kang, Department of Sport Science, Seoul National University of Science and Technology, 172 Gongneungdong, Nowon-gu, Seoul, 139-743, Korea. E-mail: eostm2000@naver.com

https://doi.org/10.21101/cejph.a4920

\section{INTRODUCTION}

It has been widely accepted that many people are involved in risky behaviours which may directly or indirectly affect adverse health outcomes (1). For instance, poor diet, smoking, and substance abuse including drugs and alcohol are included in such behaviours. The decision to experiment and possibly engage in risky behaviours may well be dependent on a variety of factors including how people perceive these behaviours as risks to their health (2).

As significant construct of most psychological theories individuals' beliefs about the consequences of their actions and risk perception related to those consequences play a key role in behaviour (3). Risk perception has been defined in a variety of ways such as perceived risk (4), and perceived vulnerability (5). In previous research, perceived risk is the individual's or group's judgment or valuation of the magnitude and likelihood of possible negative outcomes which may result from an action (6). Weinstein defined perceived susceptibility as a belief that one is susceptible to future negative outcomes and unprotected from a dangerous situation (7). Given these concepts related to the risk construct, a ready explanation for why people take risks is that they ignore or at least greatly underestimate the likelihood of negative outcomes. That is, it is generally assumed that a large volume of people tend to recognize their chances of the risks as lower than other people of the same age. A popular account of such perceptions is that individuals see themselves as invulnerable to those risks or they underestimate the likelihood of negative outcomes (8). Underestimating health risk has been conceptualized as perception bias (7). In this regard, it is important to study individual perceptions of health risks because perceptions toward health risks can primarily affect initiating or maintaining positive health behaviour, or avoiding negative one (2).

Many studies have attempted to identify how people perceive their own health risk and compare it with others $(9,10)$. Lee et al. indicated that people generally judged themselves as less vulnerable than others from various health risks such as pollution, drugs, crime, and cancer (11). In addition, Walker et al. investigated risk perception between people at higher risk and those at lower risk for developing diabetes (12). The results indicated that the high risk people showed greater comparative disease risk perception, as well as greater perception of diabetes risk. In addition, a half of higher risk people reported perception bias that they were less likely to develop diabetes than other people of the same age and gender.

Such perception bias about health risks can be related to age and gender. Finn and Brag reported that young drivers perceived less risk in speeding and night driving than did older drivers, which suggests that accident rates among youth may reflect a failure to be cognizant of or appreciate dangerous situations (13). In addition, Kim indicated that adolescents did not perceive themselves to be less likely than adults to encounter health risks such as excessive alcohol drinking, mugging and car accident (2). However, compared to adults, adolescents tended to minimize the perceived risk of experimental and occasional involvement in health-threatening activities. With regard to gender differences in health risk perception, Harris et al. indicated that men reported a greater overall likelihood of engaging in risky behaviours than women in the gambling, health and recreational domains (14). In all three domains, women judged potential negative consequences 
as more likely to occur and they judged the potential negative consequences as significantly more severe in the gambling and health domains. More recently, Lapsley and Hill investigated subjective invulnerability and perception bias in drinking, smoking and illegal drug use among college students, and found that male students scored higher on both danger invulnerability and perception bias than female counterparts (15).

Although research on health risk perceptions has been frequently carried out in the western society, there is notably little evidence to support such research in other culture including Korea. Therefore, the current study investigated how adolescents perceive their own health risks and compare their own likelihood of health risks with that of others of the same age. Moreover, the study identified the differences in health risk perceptions between males and females.

\section{MATERIALS AND METHODS}

\section{Participants}

After receiving permission from the principals and parents, 625 adolescents $(314$ males and 311 females, mean age $=14.76$ years) ranging from 7 th to 9 th grade who attended junior high schools in Seoul, Korea, voluntarily participated in a survey designed to assess their risk perception and perception bias. 640 adolescents gave their consent to participate in the study. Of those, $625(97.7 \%)$ participants completed the survey form. The remaining $15(2.3 \%)$ participants were disqualified because they failed to complete the survey form. Adolescents were excluded from the study if they had mental or physical health problems that might preclude the validity of the survey administration. This study was approved by the Research Committee of Seoul National University of Science and Technology.

\section{Measures}

The self and risk judgments profile developed by Whalen et al. (16) was translated into Korean and revised to measure participants' health risk perceptions (2). This measure has three subscales with 25 negative health-risk events individuals might experience in their lifetime (9 items for general health, 9 items for lifestyle, and 7 items for environment). The study participants were asked to indicate how they perceived the likelihood of encountering various health risks (e.g., cancer, smoking, chemicals in food, etc.) with 5-point response rates range from -2 (very unlikely) to 2 (very likely). Values less than zero indicated an optimistic tendency to claim that one's risk was less than average and values greater than zero indicated a tendency to claim that one's risk was higher than average. A score of zero indicated one's risk was perceived as average. The alpha reliabilities by domain were 0.89 for general health, 0.90 for lifestyle, and 0.84 for environment.

\section{Procedures of Translation and Validation of Measures}

The self and other risk judgment profile used in this study was translated into Korean and its reliability was supported by previous studies $(2,17)$. However, validation processes were performed for the current measure because the previous studies were conducted on adolescents. These procedures were guided by the methodology of Banville et al. (18), which resulted in measures that appeared to be both culturally appropriate and psychometrically sound. In the initial stage, the standardized self and other risk judgment measure was administered to two Korean scholars that were familiar with health risks and perceptions for additional item modifications. Through this process, content validity suitable for the purposes of the study was established. In addition, the pilot form of the self and other risk judgments measure was tested among a sample of 95 Korean adolescents of similar age to the target population to control for item clarity and response variance, and to estimate reliability. Two weeks after the initial measure was taken, the measure was administered again using the Korean pilot-based sample $(n=88)$ to evaluate their test-retest reliability.

\section{Data Analysis}

Paired $t$ tests were conducted to examine differences in participants' perceptions of self and other health risks. In addition, MANOVAs were conducted to identify the differences in health risk perceptions between male and female participants and between younger and older adolescents. All statistical methods applied in this study were conducted by SPSS 22 and a 0.05 level of significance was used to interpret tested hypotheses.

\section{RESULTS}

\section{Health Risk Perceptions of Study Participants}

Table 1 shows the result of a descriptive analysis of means and standard deviations for each health risk. The results indicated that the study participants, regardless of gender and age, tend to underestimate their vulnerability to majority of health risk events. In the self-risk events, participants perceived themselves as not being vulnerable to most health risks (e.g., illegal drugs, AIDS, homicide, etc.), meanwhile they perceived themselves as being vulnerable to flu, excessive stress, tooth decay, and air pollution. In addition, paired $t$ tests were conducted to examine the differences in participants' perceptions of self and other health risks. The findings indicated that the study participant, regardless of age and gender, have significant perception bias for all health risk events; i.e. the participants perceived their own likelihood of encountering health risks as lower than that of others (Table 1). Specifically, among the three risk domains the lifestyle domain showed the highest perception bias $(t=-19.59, \mathrm{p}<0.001)$.

\section{Perception Bias toward Health Risks by Gender and Age}

In order to identify the differences in health risk perceptions between male and female participants, MANOVA was conducted for each of the three risk domains (general health, lifestyle and environment) (Table 2). Overall, in both self and other risk events there were significant mean differences between male and female participants in all health risk domains $(\mathrm{F}(1,618)=-14.91$ for lifestyle, -10.32 for general health, -9.45 for environment, all $\mathrm{p}<0.001$ ). Specifically, male participants perceived their own likelihood of a variety of health risks as substantially lower com- 
Table 1. Differences in means and standard deviations between self and other health risk perceptions

\begin{tabular}{|c|c|c|c|}
\hline & $\begin{array}{c}\text { Self-risk } \\
\text { Mean (SD) }\end{array}$ & $\begin{array}{l}\text { Other-risk } \\
\text { Mean (SD) }\end{array}$ & $\mathrm{t}$ \\
\hline General health & $-0.29(0.75)$ & $0.05(0.74)$ & $-13.66^{* * *}$ \\
\hline Bone fracture & $-0.20(1.19)$ & $0.10(1.13)$ & $-6.42^{* *}$ \\
\hline AIDS & $-1.55(1.01)$ & $-0.91(1.13)$ & $13.32^{* *}$ \\
\hline Cancer & $-0.026(1.14)$ & $0.03(1.12)$ & $-6.72^{\star *}$ \\
\hline Diabetes & $-0.33(1.20)$ & $0.06(1.06)$ & $8.28^{* *}$ \\
\hline Severe car accident & $-0.42(1.14)$ & $-0.08(1.06)$ & $-8.61^{* *}$ \\
\hline Heart disease & $-0.31(1.18)$ & $0.04(1.05)$ & $7.84^{* \star}$ \\
\hline Tooth decay & $0.28(1.14)$ & $0.45(1.01)$ & $-3.66^{* *}$ \\
\hline Flu & $0.51(1.17)$ & $0.65(1.01)$ & $3.17^{\star *}$ \\
\hline Depression & $-0.30(1.51)$ & $0.17(1.06)$ & $-7.79^{\star \star}$ \\
\hline Lifestyle & $-0.60(0.74)$ & $-0.01(0.76)$ & $-19.59^{\star * *}$ \\
\hline Smoking & $-0.71(1.58)$ & $0.13(1.24)$ & $-12.85^{\star *}$ \\
\hline Illegal drug & $-1.66(0.84)$ & $-1.14(1.07)$ & $11.94^{\star *}$ \\
\hline Heavy drinking & $-0.22(1.47)$ & $0.38(1.21)$ & $-10.05^{\star *}$ \\
\hline Junk food & $-0.59(1.27)$ & $-0.12(1.23)$ & $10.34^{* *}$ \\
\hline Physical inactivity & $0.06(1.27)$ & $0.44(1.06)$ & $-6.49^{\star *}$ \\
\hline Obesity & $-0.31(1.36)$ & $0.31(1.05)$ & $10.38^{* *}$ \\
\hline Suicide & $-1.39(0.97)$ & $-0.68(1.10)$ & $-15.37^{\star *}$ \\
\hline Excessive stress & $0.02(1.26)$ & $0.37(1.16)$ & $15.37^{* *}$ \\
\hline Smartphone addiction & $-0.20(1.34)$ & $0.26(1.20)$ & $8.90^{* *}$ \\
\hline Environment & $-0.64(0.87)$ & $-0.29(0.90)$ & $-14.37^{\star \star *}$ \\
\hline Toxic waste & $-0.76(1.16)$ & $-0.48(1.18)$ & $-7.49^{* *}$ \\
\hline Chemicals in food & $-0.47(1.26)$ & $-0.23(1.21)$ & $6.21^{\star *}$ \\
\hline Homicide & $-1.23(1.03)$ & $-0.86(1.14)$ & $-9.26^{* *}$ \\
\hline Water pollution & $-0.59(1.15)$ & $-0.36(1.26)$ & $6.90^{* *}$ \\
\hline Fire & $-0.55(1.10)$ & $-0.30(1.06)$ & $-7.50^{\star *}$ \\
\hline Radioactive pollution & $-0.88(1.15)$ & $-0.65(1.13)$ & $6.00^{* *}$ \\
\hline Air pollution & $0.19(1.26)$ & $0.27(1.19)$ & -1.63 \\
\hline
\end{tabular}

${ }^{* *} p<0.01 ;{ }^{* * *} p<0.001$

pared to their female counterparts in self-risk events. Furthermore, the univariate ANOVAs revealed that male participants compared to female peers rated the chances of most health risks happening to them as significantly lower than others of the same age.

In addition, Table 3 presented the differences in health risk perceptions between younger and older adolescents. Like the results of gender differences significant mean differences were found in both self and other risk events of all health risks domains between younger and older adolescents $(\mathrm{F}(1,618)=-14.41$ for lifestyle, -11.38 for environment, -9.66 for general health, all $\mathrm{p}<0.001$ ). Specifically, the univariate ANOVAs revealed that younger adolescents rated the chances of most health risks happening to them as significantly lower than older counterparts.

\section{DISCUSSION AND CONCLUSION}

This study provides much needed information about health risk perception and perception bias related directly to negative health behaviours. Korean adolescents, regardless of age and gender, tended to have unrealistic perception toward a variety of health risks. They perceived that their own chances of experiencing health risks as less likely than those of other people. This finding agrees with previous studies which indicate that many individuals engage in risky behaviours in part because they underestimate the likelihood that they will experience health problems, and such underestimates have been referred to as perception bias $(2,19)$. As for underestimation and perception bias, it is possible to hold view that people have egocentric dispositions and either underestimate or ignore the risks. This underestimation has been attributed to a personal fable (20), which posits that people perceive themselves as being invulnerable and somewhat immune to risks. Inherent in egocentric thinking is a tendency to be self-absorbed, which is a direct result of personal invulnerable and unique belief (21).

Moreover, the finding indicated that Korean adolescents perceived themselves as being vulnerable (i.e. likely to experience health risks) only to certain events (e.g., tooth decay, excessive stress, air pollution, etc.). In general, people tend to have realistic 
Table 2. Results of univariate and multivariate F-test for self vs. other health risk events between male and female adolescents

\begin{tabular}{|c|c|c|c|c|c|}
\hline & \multicolumn{2}{|c|}{ Male } & \multicolumn{2}{|c|}{ Female } & \multirow[b]{2}{*}{$F(1,618)$} \\
\hline & $\begin{array}{l}\text { Self-risk } \\
\text { Mean (SD) }\end{array}$ & $\begin{array}{l}\text { Other-risk } \\
\text { Mean (SD) }\end{array}$ & $\begin{array}{l}\text { Self-risk } \\
\text { Mean (SD) }\end{array}$ & $\begin{array}{l}\text { Other-risk } \\
\text { Mean (SD) }\end{array}$ & \\
\hline General health & $-0.36(0.77)$ & $0.02(0.75)$ & $-0.22(0.73)$ & $0.09(0.73)$ & $-10.32^{* * *}$ \\
\hline Bone fracture & $-0.18(1.23)$ & $0.11(1.24)$ & $-0.25(1.17)$ & $0.09(1.00)$ & $-4.76^{* *}$ \\
\hline AIDS & $-1.51(.98)$ & $-0.76(1.21)$ & $-1.58(1.06)$ & $-1.06(1.03)$ & $11.12^{* * *}$ \\
\hline Cancer & $-0.25(1.19)$ & $0.021 .15)$ & $-0.31(1.10)$ & $0.04(1.09)$ & $-4.91^{* * *}$ \\
\hline Diabetes & $-0.32(1.27)$ & $0.041 .07)$ & $-0.39(1.14)$ & $0.07(1.04)$ & $5.71^{* \star *}$ \\
\hline Severe car accident & $-0.50(1.17)$ & $-0.10(1.09)$ & $-0.38(1.10)$ & $-0.07(1.02)$ & $-6.55^{\star * *}$ \\
\hline Heart disease & $-0.27(1.12)$ & $-0.02(1.04)$ & $-0.40(1.16)$ & $0.10(1.06)$ & $5.19^{\star \star *}$ \\
\hline Tooth decay & $0.25(1.10)$ & $0.40(1.01)$ & $0.33(1.18)$ & $0.51(1.02)$ & $-2.07^{*}$ \\
\hline Flu & $0.37(1.18)$ & $0.53(1.00)$ & $0.61(1.15)$ & $0.77(1.02)$ & $2.12^{*}$ \\
\hline Depression & $-0.53(1.68)$ & $0.05(1.04)$ & $-0.06(1.22)$ & $0.29(1.06)$ & $-6.05^{\star \star *}$ \\
\hline Lifestyle & $-0.55(0.73)$ & $0.05(0.75)$ & $-0.63(0.74)$ & $-0.05(0.77)$ & $-14.91^{* * *}$ \\
\hline Smoking & $-0.14(1.65)$ & $0.30(1.23)$ & $-1.30(1.25)$ & $-0.06(1.23)$ & $4.90^{* *}$ \\
\hline Illegal drug & $-1.53(1.00)$ & $-1.04(1.14)$ & $-1.76(0.68)$ & $-1.24(1.00)$ & $-7.99^{* * *}$ \\
\hline Heavy drinking & $0.17(1.42)$ & $0.55(1.14)$ & $-0.64(1.40)$ & $0.22(1.27)$ & $4.37^{* *}$ \\
\hline Junk food & $-0.55(1.26)$ & $-0.08(1.22)$ & $-0.62(1.30)$ & $-0.16(1.24)$ & $-7.11^{* * *}$ \\
\hline Physical inactivity & $-0.10(1.24)$ & $0.39(1.04)$ & $0.32(1.27)$ & $0.49(1.07)$ & $6.27^{\star * *}$ \\
\hline Obesity & $-0.48(1.32)$ & $0.30(1.07)$ & $-0.12(1.36)$ & $0.33(1.03)$ & $-9.06^{* * *}$ \\
\hline Suicide & $-1.42(1.00)$ & $-0.71(1.10)$ & $-1.38(0.94)$ & $-0.65(1.11)$ & $10.83^{* * *}$ \\
\hline Excessive stress & $-0.01(1.25)$ & $0.36(1.17)$ & $0.05(1.27)$ & $0.40(1.15)$ & $-4.73^{\star *}$ \\
\hline Smartphone addiction & $-0.18(1.34)$ & $0.37(1.15)$ & $-0.17(1.36)$ & $0.16(1.24)$ & $7.47^{\star * *}$ \\
\hline Environment & $-0.63(0.88)$ & $-0.29(.91)$ & $-0.64(0.86)$ & $-0.28(.89)$ & $-9.45^{\star * *}$ \\
\hline Toxic waste & $-0.73(1.17)$ & $-0.47(1.10)$ & $-0.81(1.16)$ & $-0.48(1.15)$ & $-4.04^{* *}$ \\
\hline Chemicals in food & $-0.47(1.22)$ & $-0.23(1.20)$ & $-0.50(1.28)$ & $-0.23(1.22)$ & $4.00^{* *}$ \\
\hline Homicide & $-1.20(1.07)$ & $-0.84(1.18)$ & $-1.25(1.00)$ & $-0.88(1.11)$ & $5.83^{\star \star *}$ \\
\hline Water pollution & $-0.50(1.20)$ & $-0.29(1.16)$ & $-0.70(1.10)$ & $-0.43(1.07)$ & $4.02^{* \star *}$ \\
\hline Fire & $-0.56(1.09)$ & $-0.29(1.08)$ & $-0.56(1.28)$ & $-0.30(1.03)$ & $-5.33^{\star * *}$ \\
\hline Radioactive pollution & $-1.00(1.234)$ & $-0.74(1.13)$ & $-0.76(1.17)$ & $-0.55(1.13)$ & $4.75^{\star *}$ \\
\hline Air pollution & $0.15(1.29)$ & $0.24(1.20)$ & $0.26(1.25)$ & $0.30(1.19)$ & -1.38 \\
\hline
\end{tabular}

${ }^{*} p<0.05 ;{ }^{* *} p<0.01,{ }^{* * *} p<0.001$

perceptions if some health-related risks were judged as relatively less serious for their health or future life, or are already widespread in their life. Although this result is supported by a relatively current study (2), this cannot be substantiated from Korean literature and thus, there is a need for further study to determine whether it is an aspect of Korean social context.

This study revealed that there were gender and age differences within the sample. For gender differences, the findings indicated that female adolescents exhibited greater unrealistic perception than their male counterparts. Specially, females perceived their chances as significantly lower than those of males in the same age group at almost all health risks. These results were supported by many previous studies $(22,23)$. It is plausible to explain that gender differences in risk perception could be at least partially attributed to gender socialization (24), the fact that women have less power and control (25). In other words, males are typically assumed to frequently experiment various risk behaviours compared to females due to traditional social role and more conforming behaviour in our society (26), In addition, it is well known that adult women are more aware of health warnings associated with various health risks and use health services more than men (27). Given this level of interest and awareness in health, it may be reasonable to suggest that females have every reason to perceive unrealistically.

Younger adolescents more often rely on social comparison in risk perception, judge perceived risk as smaller, and minimize the impact of periodic involvement in health-threatening activity compared to older adolescents (28). It is plausible to explain that risk perception may change during maturation due to emergence of health problems which are more likely to appear in increasing age, but also with changes in the individual's categorization of personal experiences into the temporal phase of his or her lifespan (29). In addition, Ravert et al. indicated that reasonable risk perception may increase with maturation due to a decrease in sensation seeking and decline in danger invulnerability due to greater exposure to health problems, lower optimism about avoid- 
Table 3. Results of univariate and multivariate F-test for self vs. other health risk events among younger and older adolescents

\begin{tabular}{|c|c|c|c|c|c|}
\hline & \multicolumn{2}{|c|}{ Younger adolescents } & \multicolumn{2}{|c|}{ Older adolescents } & \multirow[b]{2}{*}{$F(1,618)$} \\
\hline & $\begin{array}{c}\text { Self-risk } \\
\text { Mean (SD) }\end{array}$ & $\begin{array}{l}\text { Other-risk } \\
\text { Mean (SD) }\end{array}$ & $\begin{array}{c}\text { Self-risk } \\
\text { Mean (SD) }\end{array}$ & $\begin{array}{l}\text { Other-risk } \\
\text { Mean (SD) }\end{array}$ & \\
\hline General health & $-0.32(0.75)$ & $0.01(0.74)$ & $-0.27(0.75)$ & $0.10(0.73)$ & $-9.66^{* * *}$ \\
\hline Bone fracture & $-0.26(1.18)$ & $0.09(1.18)$ & $-0.17(1.20)$ & $0.11(1.070$ & $-5.05^{\star * *}$ \\
\hline AIDS & $-1.65(1.12)$ & $-1.14(1.10)$ & $-1.47(0.87)$ & $-0.65(1.11)$ & $6.91^{* * *}$ \\
\hline Cancer & $-0.14(1.13)$ & $0.15(1.09)$ & $-0.38(1.15)$ & $-0.07(1.13)$ & $-5.16^{\star \star *}$ \\
\hline Diabetes & $-1.18(1.23)$ & $0.17(1.02)$ & $-0.48(1.15)$ & $-0.05(1.07)$ & $5.49^{* * *}$ \\
\hline Severe car accident & $-0.47(1.11)$ & $-0.17(1.02)$ & $-0.36(1.17)$ & $0.01(1.07)$ & $-5.64^{* * *}$ \\
\hline Heart disease & $-0.08(1.17)$ & $0.16(1.05)$ & $-0.58(1.13)$ & $-0.08(1.01)$ & $3.82^{* \star}$ \\
\hline Tooth decay & $0.13(1.10)$ & $0.26(0.98)$ & $0.47(1.15)$ & $0.68(.10)$ & $-2.20^{*}$ \\
\hline Flu & $0.28(1.16)$ & $0.51(0.97)$ & $0.77(1.12)$ & $0.83(1.03)$ & $3.55^{\star *}$ \\
\hline Depression & $-0.50(1.71)$ & $0.07(1.08)$ & $-0.08(1.25)$ & $0.29(1.02)$ & $-6.28^{\star \star *}$ \\
\hline Lifestyle & $-0.82(0.66)$ & $-0.26(0.71)$ & $-0.35(0.74)$ & $0.28(0.72)$ & $-14.41^{* * *}$ \\
\hline Smoking & $-0.77(1.55)$ & $-0.18(1.28)$ & $-0.62(1.60)$ & $0.50(1.11)$ & $7.03^{* * *}$ \\
\hline Illegal drug & $-1.77(.69)$ & $-1.43(0.91)$ & $-1.53(0.97)$ & $-0.84(1.13)$ & $-6.77^{* * *}$ \\
\hline Heavy drinking & $-0.37(1.46)$ & $0.07(1.23)$ & $0.01(1.44)$ & $0.79(1.06)$ & $5.46^{* * *}$ \\
\hline Junk food & $-1.10(1.03)$ & $-0.61(1.10)$ & $-0.01(1.27)$ & $0.44(1.12)$ & $-8.56^{\star * *}$ \\
\hline Physical inactivity & $-0.01(1.22)$ & $0.40(1.01)$ & $0.21(1.31)$ & $0.52(1.08)$ & $5,53^{\star \star *}$ \\
\hline Obesity & $-0.26(1.43)$ & $0.31(1.05)$ & $-0.32(1.30)$ & $0.34(1.02)$ & $-6.74^{\star \star *}$ \\
\hline Suicide & $-1.51(0.83)$ & $-0.88(1.04)$ & $-1.23(1.10)$ & $-0.47(1.14)$ & $10.48^{\star * *}$ \\
\hline Excessive stress & $-0.14(1.25)$ & $0.26(1.17)$ & $0.24(1.12)$ & $0.55(1.10)$ & $-5.72^{\star \star \star}$ \\
\hline Smartphone addiction & $-0.81(1.09)$ & $-0.20(1.14)$ & $0.51(1.26)$ & $0.81(1.02)$ & $8.83^{* * *}$ \\
\hline Environment & $-0.90(0.77)$ & $-0.51(0.87)$ & $-0.35(0.88)$ & $-0.04(0.88)$ & $-11.38^{* * *}$ \\
\hline Toxic waste & $-1.06(1.07)$ & $-0.73(1.11)$ & $-0.43(1.18)$ & $-0.20(1.08)$ & $-5.96^{* * *}$ \\
\hline Chemicals in food & $-0.82(1.11)$ & $-0.52(1.16)$ & $-0.05(1.28)$ & $0.11(1.17)$ & $5.17^{\star * *}$ \\
\hline Homicide & $-1.36(0.93)$ & $-0.98(1.13)$ & $-1.05(1.10)$ & $-0.73(1.14)$ & $-6.64^{\star * *}$ \\
\hline Water pollution & $-0.85(1.08)$ & $-0.54(1.07)$ & $-0.28(1.16)$ & $-0.016(1.14)$ & $6.75^{* * *}$ \\
\hline Fire & $0.74(1.04)$ & $-0.42(1.04)$ & $-0.31(1.13)$ & $-0.17(1.07)$ & $-6.68^{\star \star *}$ \\
\hline Radioactive pollution & $-1.24(1.01)$ & $-0.91(1.08)$ & $-0.51(1.17)$ & $-0.38(1.12)$ & $6.00^{* * *}$ \\
\hline Air pollution & $-0.11(1.23)$ & $0.05(1.14)$ & $0.54(1.21)$ & $0.55(1.19)$ & $-2.94^{* *}$ \\
\hline
\end{tabular}

${ }^{*} p<0.05 ;{ }^{* *} p<0.01,{ }^{* * *} p<0.001$

ing harm and misfortune, a higher sense of health responsibility related to the change from the present-hedonistic perspective toward future orientation (30). However, this is not supported by previous studies. Therefore, it is suggested that further research is needed to identify realistic and unrealistic perception mechanism for a large number of people from different demographic and socioeconomic backgrounds.

The current study has several limitations. The perceived risk question asked about comparative risk, not absolute risk, and therefore results may not translate bias in absolute risk. The findings are limited to description of how people perceived various health risks and such perceptions are different between gender and age. Further studies are needed to identify a causal link between health risk perceptions and health related behaviour. The measures applied in our study underwent a rigorous and systematic translation and validation process. However, they relied on self-report, which may result in some bias from item interpretation, recall, and social desirability.
In spite of such limitations, the significance of this study lies in the fact that it made a unique contribution to the existing knowledge about health risk perceptions. Its strength was in the sample which allowed to explore a hitherto relatively unstudied ethnic group. This study suggests that further research should focus on conducting cross-cultural research and exploring possible relationship with psychological dimensions such as self-efficacy, self-esteem, and defensive optimism.

\section{Acknowledgement}

This work was supported by the Ministry of Education of the Republic of Korea and the National Research Foundation of Korea (NRF2015S1A5A2A03048588). 


\section{REFERENCES}

1. Grunbaum JA, Kann K, Kinchen S, Ross J, Hawkins J, Lowrym R, et al. Youth risk behavior surveillance - United States, 2003. MMWR Morb Mortal Wkly Rep. 2004 May 21;53(SS-2):1-95.

2. Kim Y. Preliminary finding on Korean adolescents' perceptions of health risks. Psychol Rep. 2007 Dec;101(3 Pt 1):995-1000.

3. Halpern-Felsher BL, Millstein SG, Ellen JM, Adler NE, Tschann JM, Biehl, M. The role of behavioral experience in judging risks. Health Psychol. 2001 Mar;20(2):120-6.

4. Ellen JM, Boyer CB, Tschann JM, Shafer MA. Adolescents' perceived risk for STDs and HIV infection. J Adolesc Health. 1996 Mar;18(3):177-81.

5. Perloff LS, Fetzer BK. Self-other judgment and perceived vulnerability to victimization. J Pers Soc Psychol. 1986 Mar;50(3):502-10.

6. Gough JD. A review of the literature pertaining to 'perceived' risk and 'acceptable' risk and the methods used to estimate them. Canterbury (NZ): Centre for Resource Management; 1990.

7. Weinstein ND. Unrealistic optimism about susceptibility to health problems. J Behav Med. 1982 Dec;5(4):441-60.

8. Perloff LS. Social comparison and illusions of invulnerability to negative life events. In: Snyder CR, Ford CE, editors. Coping with negative life events. The plenum series on stress and coping. Boston (MA): Springer; 1987. p. 217-42.

9. Jones SM, Gell NM, Roth JA, Scholes D, LaCroix AZ. The relationship of perceived risk and biases in perceived risk to fracture prevention behavior in older women. Ann Behav Med. 2015 Oct;49(5):696-703.

10. Steptoe A, Wright C, Kunz-Ebrecht SR, Iliffe S. Dispositional optimism and health behavior in community-dwelling older people: associations with healthy aging. Br J Health Psychol. 2006 Feb;11(Pt 1):71-84.

11. Lee JE, Lemyre L, Mercier P, Bouchard L, Krewski D. Beyond the hazard: the role of beliefs in health risk perception. Hum Ecol Risk Assess. 2005;11(6):1111-26.

12. Walker EA, Mertz CK, Kalten MR, Flynn J. Risk perception for developing diabetes: comparative risk judgments of physicians. Diabetes Care. 2003 Sep;26(9):2543-8

13. Finn P, Bragg BW. Perception of the risk of an accident by young and older drivers. Accid Anal Prev. 1986 Aug;18(4):289-98.

14. Harris CR, Jenkins M, Glaser D. Gender differences in risk assessment: why do women take fewer risks than men? Judgm Decis Mak. 2006 Jul;1(1):48-63.

15. Lapsley DK, Hill PL. Subjective invulnerability, optimism bias and adjustment in emerging adulthood. J Youth Adolesc. 2010 Aug;39(8):847-57.

16. Whalen CK, Henker B, O'Neil R, Hollingshead J, Holman A, Moore B. Optimism in children's judgments of health and environmental risks. Health Psychol. 1994 Jul;13(4):319-25.
17. Kim YH, Kang SJ, Park IK. Health risk perception according to gender and the physical activity level in middle-aged adults. Korean J Sport Psychol. 2016;27:1-8.

18. Banville D, Desrosiers P, Genet-Volet Y. Translating questionnaires and inventories using a cross-cultural translation technique. J Teach Phys Educ. 2000 Apr;19(3):374-87.

19. Nezlek JB, Zebrowski BD. Implications of the dimensionality of unrealistic optimism for the study of perceived health risks. J Soc Clin Psychol. 2001 Dec;20(4):521-37.

20. Elkind D. Egocentrism and adolescence. Child Dev. 1967 Dec;38(4):102534.

21. Lavery B, Siegel AW, Cousins JH, Rubovits DS. Adolescent risk taking an analysis of problem behavior in problem children. J Exp Child Psychol. 1993 Apr;55(2):277-94.

22. Bassett RL, Martin Ginis KA. Risky business: the effects of an individualized health information intervention on health risk perceptions and leisure time physical activity among people with spinal cord injury. Disabil Health J. 2011 Jul;4(3):165-76.

23. Renner B, Schupp HT. The perception of health risk. In: Friedman HS, editor. The Oxford handbook of health psychology. New York: Oxford University Press; 2011. p. 637-65.

24. Davidson DJ, Freudenburg WR. Gender and environmental risk concerns: a review and analysis of available research. Environ Behav. 1996 May;28(3):302-29.

25. Finucane ML, Slovic P, Mertz CK, Flynn J, Satterfield TA. Gender, race, and perceived risk: the 'white male' effect. Health Risk Soc. 2000 Jul;2(2):159-72.

26. Borrelli B, Hayes RB, Dunsiger S, Fava JL. Risk perception and smoking behavior in medically ill smokers: a prospective study. Addiction. 2010 Jun;105(6):1100-8.

27. Maričíć J, Sučíć I, Šakić V. Risk perception related to (il)licit substance use and attitudes toward its use and legalization: the role of age, gender, and substance use. J Gen Soc Iss. 2013 Dec;22(4):579-99.

28. Mravčik V, Korčišová B, Lejčková P, Miovská L, Škrdlantová E, Petroš O, Sklenař V, Vopravil J. Annual report: the Czech Republic 2004 drug situation. Prague: Office of the Government of the Czech Republic. 2005.

29. Sharma M. Health belief model: need for more utilization in alcohol and drug education. J Alcohol Drug Educ. 2011 Apr;55(1):3-6.

30. Ravert RD, Schwartz SJ, Zamboanga BL, Kim SY, Weisskirch RS, Bersamin M. Sensation seeking and danger invulnerability: paths to college student risk-taking. Pers Indiv Differ. 2009 Nov;47(7):763-8.

Received September 6, 2016 Accepted in revised form June 27, 2017 